Article

\title{
Tourism Development and Economic Growth in Southeast Asian Countries under the Presence of Structural Break: Panel Kink with GME Estimator
}

\author{
Paravee Maneejuk, Woraphon Yamaka * ${ }^{\mathbb{D}}$ and Wilawan Srichaikul
}

check for

Citation: Maneejuk, P.; Yamaka, W.; Srichaikul, W. Tourism Development and Economic Growth in Southeast Asian Countries under the Presence of Structural Break: Panel Kink with GME Estimator. Mathematics 2022, 10, 723. https://doi.org/10.3390/ math10050723

Academic Editors: Maria-Isabel Ayuda and María Dolores Gadea Rivas

Received: 23 January 2022

Accepted: 21 February 2022

Published: 24 February 2022

Publisher's Note: MDPI stays neutral with regard to jurisdictional claims in published maps and institutional affiliations.

Copyright: (C) 2022 by the authors. Licensee MDPI, Basel, Switzerland. This article is an open access article distributed under the terms and conditions of the Creative Commons Attribution (CC BY) license (https:// creativecommons.org/licenses/by/ $4.0 /)$.
Center of Excellence in Econometrics, Faculty of Economics, Chiang Mai University, Chiang Mai 50200, Thailand mparavee@gmail.com or paravee.m@cmu.ac.th (P.M.); wilawan.41oil@gmail.com (W.S.)

* Correspondence: woraphon.econ@gmail.com or woraphon.yamaka@cmu.ac.th

\begin{abstract}
This study examines the nonlinear impact of tourism development on economic growth in Southeast Asian countries using the panel kink regression model. Due to the paucity of Southeast Asian data, we may face the overparameterization problem in our model. To deal with this problem, this study proposes the Generalized Maximum Entropy (GME) estimator to estimate the unknown parameters in this nonlinear model. Several important tourism development indicators consisting of the total international arrivals, international tourism expenditure, and tourism receipts are considered. In addition, we also consider the gross capital formation and real effective exchange rate as a control variable in our nonlinear model. Our findings show that the effect of international tourist arrivals on economic growth should be separated into two regimes, while other factors do not exhibit a nonlinear relationship with Southeast Asian economic growth. Thus, we construct the empirical model with the kink effect in the variable of international tourist arrivals. To confirm the performance of the GME estimator, we compare it to the ordinary least squares and the fixed effect estimators. According to the mean squared and root means squared errors, we find that our GME estimator performs better than the ordinary least squares and the fixed effect estimators. This indicates that GME estimation is an applicable method for estimating the nonlinear effect of tourism growth on economic growth. Our empirical results show that there are positive impacts of tourism growth on economic growth for regime 1 (low tourism demand) and regime 2 (high tourism demand) with the effect of the low tourist arrivals regime being relatively larger. We also find a positive influence of gross capital formation, real effective exchange rate, international tourism expenditure, and tourism receipts on Southeast Asian economic growth.
\end{abstract}

Keywords: economic growth; entropy; panel kink regression; Southeast Asian; tourism development

MSC: 94A17; 62J02; 62P20

\section{Introduction}

Tourism is one of the largest and rapidly growing sectors in the world. Many developing economies rely heavily on this service sector for the purpose of sustainable economic growth [1,2].

Nowadays, tourism has become one of the major industries in many countries, particularly the emerging economies, with its development playing a key role in increasing income and creating new employment opportunities in the tourism-related sectors and for the country. Tourism activities can contribute positively beyond an individual economy to the regional and global economy as well (see [3,4]). As a part of the emerging tourists' places of interest worldwide, the Southeast Asian (Association of South-East Asian) countries are among the top growing tourism destinations, accounting for about one-third of the international tourist arrivals. Southeast Asian countries have an abundance and diversity of natural, economic, and cultural resources, offering great potential for tourism development. 
Under the Southeast Asian Economic Community (AEC), an integrated single market and product base, tourism is viewed as an important economic component of the Southeast Asian members, especially for Cambodia, Lao PDR, Malaysia, the Philippines, and Thailand, where the share of the tourism sector generally accounts for more than $10 \%$ of GDP. According to the statistics compiled by the World Travel and Tourism Council (WTTC) in 2013, the Southeast Asian members generated US\$112.6 billion in tourism exports or foreign exchange earnings and \$294.4 billion in value added linked to the travel and tour operations, shopping, entertainment, transportation, and various other tourism-related service occupations and productive sectors, accounting for $12.30 \%$ of the regional GDP (ASEAN Tourism Strategic Plan 2016-2025, 2015). In addition, according to the Pacific Asia Travel Association (PATA), Southeast Asia was the fastest-growing destination region in the world in 2016. With the expansion of Asian tourism, Southeast Asia has become one of the most attractive tourist destinations; hence, the tourism sector is viewed as one of the main contributors to revenues and employment of the Southeast Asian countries. Therefore, governments need to build collaborative partnerships with public, private, and non-government entities to create the institutional and promotional infrastructure for channeling tourists to their countries.

Tourism's contribution to economic development has been well-documented, and this relationship can be explained by the Tourism-Led-Growth Hypothesis (TLGH). Many studies in the past concentrated on the analysis of the growth-tourism relationship, with ignorance of the nonlinear, heterogeneous, and time-varying circumstances. Such ignorance may be one of the reasons giving rise to divergent results from the studies on the economic growth-tourism relationship. However, many more-recent studies related to the TLGH have found evidence of the nonlinear relationship between tourism and economic growth [5-8]. They have shown that the effects of tourism on economic growth in tourism-based and nontourism-based countries are different in terms of degree. The non-tourism-based countries grew at a lower rate than the tourism-based countries. As indicated by Wang [9], it is quite possible that the linear framework oversimplifies the tourism-growth relationship and that the underlying relationship between the variables is indeed complex and nonlinear in nature. Ridderstaat, Croes, and Nijkamp [10] also argued that the tourism-growth relationship could not be strictly linear since the effects of tourism on economic growth adhere to the law of diminishing returns. Regarding the problems of heterogeneity and time variation, Hsiao [11] indicated that in the presence of cross-sectional heterogeneity, assuming a common impact of a specific variable on other variables within the panel data context may be misleading. To tackle these problems, we intend to use the nonlinear model to investigate the factors affecting tourism development in Southeast Asian. Therefore, in this study, the panel kink regression approach as proposed by Tibprasorn, Maneejuk, and Sriboonchitta [12] and Zhang, Zhou, and Jiang [13] is employed. However, with the small sample data of some Southeast Asian countries (especially Lao, Cambodia, and Myanmar), the least squares (LS) estimation may not yield a reliable result of the panel kink regression and may provide highly biased parameters or, sometimes, no solution [14]. Button et al. [15] suggested that it is often hard to get meaningful results when the sample size is small. To deal with this problem, the Generalized Maximum Entropy (GME) approach of Golan, Judge, and Miller [16] and Akdeniz, Çabuk, and Güler [17] is suggested for the panel kink regression model estimation. This method also performs well when the data is affected by multicollinearity and insufficient sample size [16].

The purpose and contribution of this paper are as follows: firstly, this study contributes to the body of literature by applying a novel nonlinear model called panel kink regression to investigate the structural change in the relationship between tourism development and economic growth in ten Southeast Asian countries and its corresponding turning point. To the best of our knowledge, this is the first attempt to explore the nonlinear effect of tourism development on economic growth in all ten Southeast Asian countries. Secondly, as we deal with the small sample sizes of Southeast Asian countries, the problems of low degree of freedom and overparameterization may occur. We thus introduce the GME estimator to the 
panel kink regression model. We are the first paper to utilize the panel kink regression with GME estimation to investigate the impact of tourism (high and low tourism arrival regimes) on the Southeast Asian economies. Finally, this study also differs from previous studies in such a way that we explore the appropriate support vector for the GME estimation.

This study is organized as follows. Section 2 briefly reviews some of the previous literature, and Section 3 outlines the econometric methodology employed. Section 4 discusses the empirical findings and their policy implications. Section 5 is devoted to concluding remarks.

\section{Literature Review}

On empirical grounds, many studies have aimed to investigate the effect of tourism on economic growth. One of the tourism development hypotheses postulated in the literature is the Tourism-Led Growth Hypothesis (TLGH), which is derived directly form the Export-Led-Growth Hypothesis that considers exports as a driver of economic growth. Thus, exports and tourism in the same way contribute positively to economic growth, either through improving the allocation of production factors or by expanding resources, goods and services [18]. The TLGH aims to analyze the relationship between tourism and economic growth in both the short term and long term. Ertugrul and Mangir [3] confirmed that tourism positively affects gross domestic product and economic growth both in the long term and short term. The justification for the effect of tourism on economic growth is found in Antonakakis, Dragouni, and Filis [19]. They proposed that tourism (i) increases foreign exchange earnings which in turn can be used to finance imports, (ii) encourages investment and drives local firms towards greater efficiency due to the increased competition, (iii) alleviates unemployment, since tourism activities are heavily based on human capital, and (iv) leads to buoyant economies of scale, thus decreasing production costs for local businesses.

These bring us to view tourism as the positive factor affecting economic growth through different channels. Brida, Carrera, and Risso [20] suggested several tourism channels: first, tourism creates inflows of foreign exchange and constitutes an essential source of financial resources for the host country, which can be used to invest in capital goods thereby increasing production [21]. Second, tourism plays a vital role in stimulating investments in new infrastructure and competition. Third, tourism stimulates other economic industries by both direct and indirect effects. Fourth, tourism generates employment and increases income. Tourism is regarded among the most prominent of the service sectors and vital global industries and it is responsible for creating millions of jobs worldwide [22]. Fifth, tourism causes economies of scale. Finally, tourism is an essential factor in the diffusion of technical knowledge, research and development, and human capital accumulation.

Empirically, there have been various TLGH-related studies. Balaguer and CantavellaJorda [23] used the trivariate model of real GDP, real international tourism earnings, and real effective exchange rate to examine the role of tourism in the Spanish long-run economic development and confirmed the tourism-led growth hypothesis through cointegration and causality testing. The study used quarterly data for the period of 1975Q1-1997Q4 and found that economic growth in Spain had been sensitive to a persistent expansion of international tourism. Their results of the Granger causality test indicated that tourism affects Spain's economic growth unidirectionally, thus supporting the tourism-led growth hypothesis.

Chen and Chiou-Wei [23] showed that the tourism-led economic growth hypothesis held in Taiwan and South Korea. Lee and Chang [24] investigated the causal relationship between tourism development and economic growth for OECD and non-OECD countries (including those in Asia, Latin America, and Sub-Saharan Africa) over the 1990-2002 period. The evidence obtained in their study indicated that there is a unidirectional causal relationship between tourism development and economic growth in OECD countries, a bidirectional relationship in non-OECD countries, and only a weak relationship in Asia. Dritsakis [25] recently analyzed whether the TLGH could be verified in seven Mediterranean countries and examined the relationship between tourism development 
and economic growth. This study differs from previous studies in that it applies a new heterogeneous panel cointegration technique to reinvestigate the long-run co-movements. The results showed solid evidence of the panel cointegration relationships between tourism development and GDP; in this case, tourist receipts significantly impacted GDP in all seven Mediterranean countries.

There have been many studies that have investigated the causal effect of tourism on economic growth. Arslanturk, Balcilar, and Ozdemir [26] investigated the causal link between tourism receipts and GDP in Turkey for the period 1963-2006. They used the rolling window and time-varying coefficients estimation methods to analyze the Granger causality based on the vector error correction model (VECM). They found no Granger causality between the series, while their findings from the time-varying coefficients model in the state-space form and the rolling window technique also show that GDP has no predictive power for tourism receipts. However, tourism receipts had a positive predictive content for GDP following the early 1980s.

Tourism contributes to generating employment and hence to increasing income. As stated previously, tourism is a key source of employment that activates income for residents through multiplier effects of tourism expenditure to finance local businesses. A part of this income is allocated for repaying the production factors (i.e., wages, rents, and interest payments), and a part becomes profit. This extra income then activates new consumption that produces further economic benefits and income amongst local economic agents. Nevertheless, the contribution of the hospitality sector to the local economy may not be homogenous [20].

Based on the aforementioned literature, we can deduce that the tourism sector plays an important role in the economic expansion under investigation. However, Arslanturk, Balcilar, and Ozdemir [26] and Tang and Tan [27] questioned the stability of the tourismgrowth connection, showing that the magnitude of the connection fluctuates over time. Thus, in evaluating the causal relationship between tourism and economic growth, one needs to consider the problems of nonlinearity, heterogeneity, and time variation. Yet, these issues that plague the estimation may fail to define the relationship between tourism development and economic growth. Isik, Dogru and Turk [28] and Chang, Khamkaew, McAleer, Tansuchat [6] suggested that when the nonlinear model is not taken into account, we cannot obtain accurate and reliable results.

Consequently, we can state that the nonlinear, heterogeneous, time-varying circumstance cannot be ignored. To date, very few empirical tourism studies have focused on either the discontinuous (unconstrained) threshold model or the regime-switching model; the relevant papers include Lee and Chang [24], Chang, Khamkaew, McAleer, Tansuchat [6], Chiang, Sung, Lei [7], Valadkhani and O'Mahony [8] and Zhang and Cheng [29]. The threshold model tries to split the regression line into two or more segments based on the threshold indicator, while the Markov switching model considers the hidden Markov chain to split the regression. However, there is doubt whether these non-liner models explain accurately the relationship between tourism development and economic growth as they split the regression for the whole equation system. Moreover, we suspect that some explanatory variables might not have a nonlinear relationship with the dependent variable; therefore, allowing all the coefficients to be governed by the threshold indicator or hidden Markov chain will yield a low-efficiency result. To overcome this problem, the kink regression approach is employed in this study. The model has a continuous function concerning covariate variables, but the slope function is discontinuous at the kink or turning point in the slope with respect to some covariates which have a nonlinear relationship with the dependent variable. The regression kink model might be appealing for tourism applications where the kink effect focuses on some variables, and there is no reason to expect a kink effect in all covariates. Thus, we can have both linear and nonlinear relationships of covariate and dependent variables in the model to be estimated. 


\section{Methods}

\subsection{The Model}

In this study, we consider the panel kink regression model with an unknown threshold. To be precise, the panel-data regression model was extended to allow the nonlinear structure by incorporating in it the kink parameter; then, we have a panel-data kink regression model expressed as follows:

$$
Y_{i t}=\sum_{k=1}^{K}\left(\left(X_{k, i t}-\gamma_{k}\right)_{-} \beta_{k}^{-}+\left(X_{k, i t}-\gamma_{k}\right)_{+} \beta_{k}^{+}\right)+\sum_{g=1}^{G} D_{g, i t} \theta_{g}+u_{i}+\varepsilon_{i t},
$$

where $i=1, \ldots, N$ indexes the individual and $t=1, \ldots, T$ indexes time. $Y_{i t}$ is the dependent variable of individual $i$ at time $t, X_{1, i t}, \ldots, X_{K, i t}$ are regime-dependent explanatory variables of individual $i$ at time $t$, while $D_{1, i t}, \ldots, D_{g, i t}$ are regime-independent explanatory variables of individual $i$ at time $t$. The model consists of two error components $u_{i}$ representing the unobserved heterogeneity of the $i$ th individual, which can be correlated with $X_{k, i t}$ and $D_{g, i t}$; and $\varepsilon_{i t}$ representing a zero mean idiosyncratic random disturbance. To divide the regressor $X_{k, i t}$ into two regimes, kink or threshold parameter $\left(\gamma_{k}\right)$; $(A)_{-}=\min \left[X_{k, i t}^{\prime}-\gamma_{k}, 0\right]$ and $(A)_{+}=\max \left[X_{k, i t}^{\prime}-\gamma_{k}, 0\right]$ functions are incorporated in the model. Thus, we have $\beta^{-}$and $\beta^{+}$as the slope parameters associated with the lower and upper regimes, respectively. Note that $D_{g, i t}$ has a linear relationship with $Y_{i t}$, therefore, $\theta_{g}$ is a regime-independent coefficient of variable $g$. In this model, the individual-specific effect error components $u_{i}$ and $\varepsilon_{i t}$ are assumed to be independent and it is also assumed that $u_{i}$ varies across individuals but is constant over time.

\subsection{Estimation}

In this study, the maximum entropy concept of Jaynes [30] for estimating the unknown probabilities of a discrete probability distribution is considered for the model estimation. Under this maximum entropy principle, one chooses the distribution for which the information is just sufficient to determine the probability assignment. In this study, the Shannon's entropy [31] measure is considered as the objective function of the estimation, that is

$$
H(p)=-\sum_{k} p_{k} \log p_{k}
$$

where $p_{k}$ is the probability of the entropy function and $\sum_{k} p_{k}=1$.

We then apply the GME method to solve the inverse problem or ill-posed problem of the panel kink regression model. We follow the works of Sriboochitta et al. [32] and Tibprasorn, Maneejuk, and Sriboonchitta [12], and Zhang, Zhou, and Jiang [13] to estimate all unknown parameters in Equation (1), say $\left(\beta_{1}^{-}, \ldots, \beta_{K}^{-}\right),\left(\beta_{1}^{+}, \ldots, \beta_{K}^{+}\right)$, and $\left(\theta_{1}, \ldots, \theta_{g}\right)$. each parameter can be estimated as an expectation of probability with $M$ support values, $z=\left[z_{1}, \ldots, \bar{z}_{M}\right]$, where $z$ and $\bar{z}_{M}$ denote, respectively, the lower and the upper bounds. Thus, we can parameterize $\beta_{k}^{-}, \beta_{k}^{+}$and $\theta_{g}$ as

$$
\begin{gathered}
\beta_{k}^{-}=\sum_{m} z_{k m}^{-} p_{k m}^{-}, X_{k, i t} \leq \gamma_{k} \\
\beta_{k}^{+}=\sum_{m} z_{k m}^{+} p_{k m}^{+}, X_{k, i t}>\gamma_{k} \\
\theta_{g}=\sum_{m} z_{g m} r_{g m},
\end{gathered}
$$

where $p_{k m}^{-}, p_{k m}^{+}, r_{g m}$ are probability estimates specified on the supports $z_{k m}^{-}, z_{k m}^{+}$and $z_{g m}$, respectively. Golan, Judge, and Miller [16] assumed that the support vector is a block diagonal. The support points for any parameter do not directly affect any of the other parameter estimates. However, in the real data analysis, it is difficult to specify the support bound. Therefore, the prior information is needed in the estimation using GME. 
For the threshold or kink parameter $\gamma_{k}$, it is also considered as a discrete random variable with $M$ support values, $q_{k}=\left[q_{k 1}, \ldots, \bar{q}_{k M}\right]$, where $q_{k 1}$ and $\bar{q}_{k M}$ are, respectively, the lower and the upper bounds of $\gamma_{k}$, thus, $\gamma_{k}$ can be computed by

$$
\gamma_{k}=\sum_{m} q_{k m} h_{k m}
$$

where $h_{k}=\left[h_{k 1}, \ldots, h_{k M}\right]$ is an $M$-dimensional vector of positive weights that sum to one.

Just like the estimated parameters, the error $\varepsilon_{i t}$ is also viewed as the expected mean value of finite support $v_{i t}$. Golan, Judge, and Miller [16] assumed that the errors can be bounded in $v_{i t}=\left[\underline{v}_{i t 1}, \ldots, \bar{v}_{i t M}\right]$. Let $\underline{v}_{i t 1}$ be the smallest possible value of $\varepsilon_{i t}$ and $\bar{v}_{i t M}$ be the largest possible value of $\varepsilon_{i t}$, then each $\varepsilon_{i t}$ is defined on the vector of weights $w_{i t}=\left[w_{i t 1}, \ldots, w_{i t M}\right]$ such that

$$
\varepsilon_{i t}=\sum_{m} v_{i t m} w_{i t m}
$$

In practice, it is difficult to determine the appropriate bounds in the panel kink regression model. Following the suggestion of Pukelsheim [33], Golan, Judge, and Miller [16] on the $3 \sigma$ rule for setting the error bounds, then $\underline{v}_{i t 1}=-3 \sigma$ and $\bar{v}_{i t M}=3 \sigma$, where $\sigma$ is the standard deviation of the dependent variable. Finally, the individual-specific effect error component $u_{i}$ can be expressed as

$$
u_{i}=\sum_{m} b_{i m} f_{i m}
$$

where $f_{i}=\left[f_{i 1}, \ldots, f_{i M}\right]$ is an $M$-dimensional vector of positive weights, and $u_{i}$ can be bounded in $b_{i}=\left[\underline{b}_{i 1}, \ldots, \bar{b}_{i M}\right]$, with $\underline{b}_{i 1}$ and $\bar{b}_{i M}$ are the lowest and the highest values of $u_{i}$, respectively.

To simplify the derivation of the GME estimator, we rewrite Equation (1) in matrix form as

$$
\mathbf{Y}=\left(\mathbf{X}-i_{T} \boldsymbol{\gamma}\right)_{-} \boldsymbol{\beta}^{-}+\left(\mathbf{X}-i_{T} \boldsymbol{\gamma}\right)_{+} \boldsymbol{\beta}^{+}+\mathbf{D} \theta+\left(\mathbf{I}_{N} \otimes i_{T}\right) \mathbf{u}+\varepsilon,
$$

where $\mathbf{Y}$ is now of dimension $N T \times 1, \mathbf{X}$ is $N T \times K, \beta^{-}$and $\beta^{+}$are $K M \times 1, \gamma$ is $1 \times K$, $\mathbf{D}$ is $N T \times G, \theta$ is $G \times 1, \mathbf{u}$ is $N \times 1$ and $\varepsilon$ is $N T \times 1$. Note that $I_{N}$ is a $N \times N$ identity matrix and $i_{T}$ is a $T \times 1$ vector of ones, and $\otimes$ denotes the Kronecker product. By using the reparameterized parameters $\beta_{k}^{-}, \beta_{k}^{+}, \theta_{g}, \gamma_{k}, u_{i}$, and the error $\varepsilon_{i t}$, we can rewrite the Equation (8) as

$$
\mathbf{Y}=\left(\mathbf{X}-i_{T}(\mathbf{Q h})\right)_{-} \mathbf{Z}^{-} \mathbf{p}^{-}+\left(\mathbf{X}-i_{T}(\mathbf{Q h})\right)_{+} \mathbf{Z}^{+} \mathbf{p}^{+}+\mathbf{D Z r}+\left(\mathbf{I}_{N} \otimes i_{T}\right) \mathbf{B f}+\mathbf{V w},
$$

where $\mathbf{Z}^{-}$is $K \times K M, \mathbf{p}^{-}$is $K M \times 1, \mathbf{Z}^{+}$is $K \times K M, \mathbf{p}^{+}$is $K M \times 1, \mathbf{Q}$ is $K \times K M, \mathbf{h}$ is $K M \times 1, \mathbf{D}$ is $N T \times G, \mathbf{Z}$ is $G \times G M, \mathbf{r}$ is $G M \times 1, \mathbf{B}$ is $N \times N M, \mathbf{f}$ is $N M \times 1, \mathbf{w}$ is $N T M \times 1$, and $\mathbf{V}$ is $N T \times N T M$ matrix. We assume that the unknown probabilities on the parameter and the weight on the error are independent and they can be estimated jointly by solving the constrained optimization problem. To derive the unknown probability estimates in Equation (9), the constrained optimization problem is constructed as follows:

$$
\begin{aligned}
\mathbf{H}\left(\mathbf{p}^{-}, \mathbf{p}^{+}, \mathbf{h}, \mathbf{r}, \mathbf{f}, \mathbf{w}\right)=\underset{\mathbf{p}^{-}, \mathbf{p}^{+}, \mathbf{h}, \mathbf{r}, \mathbf{f}, \mathbf{w}}{\operatorname{argmax}}\left\{\mathbf{H}\left(\mathbf{p}^{-}\right)+\mathbf{H}\left(\mathbf{p}^{+}\right)+\mathbf{H}(\mathbf{h})+\mathbf{H}(\mathbf{r})+\mathbf{H}(\mathbf{f})+\mathbf{H}(\mathbf{w})\right\} \\
-\mathbf{p}^{-\prime} \log \left(\mathbf{p}^{-}\right)-\mathbf{p}^{+\prime} \log \left(\mathbf{p}^{+}\right)-\mathbf{h}^{\prime} \log (\mathbf{h})-\mathbf{r}^{\prime} \log (\mathbf{r})-\mathbf{f}^{\prime} \log (\mathbf{f})-\mathbf{w}^{\prime} \log (\mathbf{w}),
\end{aligned}
$$

subject to

$$
\begin{gathered}
\mathbf{Y}=\left(\mathbf{X}-i_{T}(\mathbf{Q h})\right)_{-} \mathbf{Z}^{-} \mathbf{p}^{-}+\left(\mathbf{X}-i_{T}(\mathbf{Q h})\right)_{+} \mathbf{Z}^{+} \mathbf{p}^{+}+\mathbf{D Z} \mathbf{Z}+\left(\mathbf{I}_{N} \otimes i_{T}\right) \mathbf{B f}+\mathbf{V w}, \\
i_{K}=\left(\mathbf{I}_{K} \otimes i^{\prime}{ }_{M}\right) \mathbf{p}^{-} \\
i_{K}=\left(\mathbf{I}_{K} \otimes i^{\prime}{ }_{M}\right) \mathbf{p}^{+}
\end{gathered}
$$




$$
\begin{aligned}
i_{K} & =\left(\mathbf{I}_{K} \otimes i^{\prime}{ }_{M}\right) \mathbf{h} \\
i_{G} & =\left(\mathbf{I}_{G} \otimes i^{\prime}{ }_{M}\right) \mathbf{r} \\
i_{\mathbf{N}} & =\left(\mathbf{I}_{\mathbf{N}} \otimes i^{\prime}{ }_{\mathbf{M}}\right) \mathbf{f} \\
i_{N T} & =\left(\mathbf{I}_{N T} \otimes i^{\prime}{ }_{M}\right) \mathbf{w}
\end{aligned}
$$

Then, the Largrangian function is

$$
\begin{aligned}
\mathbf{L}= & -\mathbf{p}^{-\prime} \log \left(\mathbf{p}^{-}\right)-\mathbf{p}^{+\prime} \log \left(\mathbf{p}^{+}\right)-\mathbf{h}^{\prime} \log (\mathbf{h})-\mathbf{r}^{\prime} \log (\mathbf{r})-\mathbf{f}^{\prime} \log (\mathbf{f})-\mathbf{w}^{\prime} \log (\mathbf{w}) \\
& +\lambda^{\prime}\left[\mathbf{Y}-\left(\mathbf{X}-i_{T}(\mathbf{Q h})\right) \mathbf{Z}^{-} \mathbf{p}^{-}-\left(\mathbf{X}-i_{T}(\mathbf{Q h})\right)_{+} \mathbf{Z}^{+} \mathbf{p}^{+}-\mathbf{D Z r}-\left(\mathbf{I}_{N} \otimes i_{T}\right) \mathbf{B f}-\mathbf{V w}\right]+\rho\left[i_{K}-\left(\mathbf{I}_{K} \otimes i_{M}^{\prime}\right) \mathbf{p}^{-}\right] \\
& +\Phi\left[i_{K}-\left(\mathbf{I}_{K} \otimes i_{M}^{\prime}\right) \mathbf{p}^{+}\right]+\phi\left[i_{K}-\left(\mathbf{I}_{K} \otimes i_{M}^{\prime}\right) \mathbf{h}\right]+\vartheta\left[i_{G}-\left(\mathbf{I}_{G} \otimes i_{M}^{\prime}\right) \mathbf{r}\right]+\varphi\left[i_{N}-\left(\mathbf{I}_{N} \otimes i_{M}^{\prime}\right) \mathbf{f}\right] \\
& +\varsigma\left[i_{N T}-\left(\mathbf{I}_{N T} \otimes i_{M}^{\prime}\right) \mathbf{w}\right],
\end{aligned}
$$

where $\lambda, \rho, \Phi, \phi, \vartheta, \varphi, \varsigma$ are vectors of Lagrangian multiplier. Taking the gradient of $\mathbf{L}$ to derive the first-order conditions, we have

$$
\begin{aligned}
& \nabla_{\mathbf{p}^{-}} \mathbf{L}=-\log \left(\mathbf{p}^{-}\right)-i_{K M}-\mathbf{Z}^{\prime}\left(\mathbf{X}-i_{T}(\mathbf{Q h})\right)^{\prime}{ }_{-} \boldsymbol{\lambda}-\left(\mathbf{I}_{K} \otimes i_{M}\right) \rho=0, \\
& \nabla_{\mathbf{p}^{+}} \mathbf{L}=-\log \left(\mathbf{p}^{+}\right)-i_{K M}-\mathbf{Z}^{\prime}\left(\mathbf{X}-i_{T}(\mathbf{Q h})\right)^{\prime}{ }_{+} \boldsymbol{\lambda}-\left(\mathbf{I}_{K} \otimes i_{M}\right) \Phi=0, \\
& \nabla_{r} \mathbf{L}=-\log (\mathbf{r})-i_{G M}-\mathbf{Z}^{\prime} \mathbf{D}^{\prime} \boldsymbol{\lambda}-\left(\mathbf{I}_{G} \otimes i_{M}\right) \vartheta=0, \\
& \nabla_{h} \mathbf{L}=-\log (\mathbf{h})-i_{K}-\mathbf{Z}^{\prime}(\mathbf{Q})_{-} \boldsymbol{\lambda}-\mathbf{Z}^{\prime}(\mathbf{Q})_{+} \boldsymbol{\lambda}-\left(\mathbf{I}_{K} \otimes i_{M}\right) \phi=0, \\
& \nabla_{f} \mathbf{L}=-\log (\mathbf{f})-i_{N M}-\mathbf{B}^{\prime}\left(\mathbf{I}_{\mathbf{N}} \otimes i_{T}^{\prime}\right) \boldsymbol{\lambda}-\left(\mathbf{I}_{\mathbf{N}} \otimes i_{\mathbf{M}}\right) \varphi=0, \\
& \nabla_{w} \mathbf{L}=-\log (\mathbf{w})-i_{N T M}-\mathbf{V}^{\prime} \boldsymbol{\lambda}-\left(\mathbf{I}_{N T} \otimes i_{M}\right) \varsigma=0, \\
& \nabla_{\lambda} \mathbf{L}=\mathbf{Y}-\left(\mathbf{X}-i_{T}(\mathbf{Q h})\right)_{-} \mathbf{Z}^{-} \mathbf{p}^{-}-\left(\mathbf{X}-i_{T}(\mathbf{Q h})\right)_{+} \mathbf{Z}^{+} \mathbf{p}^{+}-\mathbf{D Z r}-\mathbf{B f}-\mathbf{V w}, \\
& \nabla_{\rho} \mathbf{L}=i_{K}-\left(\mathbf{I}_{K} \otimes i_{M}^{\prime}\right) \mathbf{p}^{-}, \\
& \nabla_{\Phi} \mathbf{L}=i_{K}-\left(\mathbf{I}_{K} \otimes i_{M}^{\prime}\right) \mathbf{p}^{+}, \\
& \nabla_{\phi} \mathbf{L}=i_{K}-\left(\mathbf{I}_{K} \otimes i^{\prime}{ }_{M}\right) \mathbf{h}, \\
& \nabla_{\vartheta} \mathbf{L}=i_{G}-\left(\mathbf{I}_{G} \otimes i_{\mathbf{M}}^{\prime}\right) \mathbf{r}, \\
& \nabla_{\varphi} \mathbf{L}=i_{\mathbf{N}}-\left(\mathbf{I}_{\mathbf{N}} \otimes i_{\mathbf{M}}^{\prime}\right) \mathbf{f}, \\
& \nabla_{\zeta} \mathbf{L}=i_{N T}-\left(\mathbf{I}_{N T} \otimes i^{\prime}{ }_{M}\right) \mathbf{w},
\end{aligned}
$$

After some algebra, we obtain

$$
\begin{gathered}
\mathbf{p}^{-}=\exp \left(-\mathbf{Z}^{\prime}\left(\mathbf{X}-i_{T}(\mathbf{Q h})\right)^{\prime}{ }_{-} \boldsymbol{\lambda}\right) \odot \exp \left[-i_{K M}-\left(\mathbf{I}_{K} \otimes i_{M}\right) \rho\right], \\
\mathbf{p}^{+}=\exp \left(-\mathbf{Z}^{\prime}\left(\mathbf{X}-i_{T}(\mathbf{Q h})\right)^{\prime}{ }_{+} \boldsymbol{\lambda}\right) \odot \exp \left[-i_{K M}-\left(\mathbf{I}_{K} \otimes i_{M}\right) \Phi\right], \\
\mathbf{r}=\exp \left(-\mathbf{Z}^{\prime} \mathbf{D}^{\prime} \boldsymbol{\lambda}\right) \odot \exp \left[-i_{G M}-\left(\mathbf{I}_{G} \otimes i_{M}\right) \vartheta\right], \\
\mathbf{h}=\exp \left(-\mathbf{Z}^{\prime}(\mathbf{Q})_{-} \boldsymbol{\lambda}\right)-\exp \left(-\mathbf{Z}^{\prime}(\mathbf{Q})_{+} \boldsymbol{\lambda}\right) \odot \exp \left[-i_{K}-\left(\mathbf{I}_{K} \otimes i_{M}\right) \phi\right], \\
\mathbf{f}=\exp \left(-\mathbf{B}^{\prime} \boldsymbol{\lambda}\right) \odot \exp \left[-i_{N M}-\left(\mathbf{I}_{\mathbf{N}} \otimes i_{\mathbf{M}}\right) \varphi\right]=0, \\
\mathbf{w}=\exp \left(-\mathbf{V}^{\prime} \boldsymbol{\lambda}\right) \odot \exp \left[-i_{N T M}-\left(\mathbf{I}_{N T} \otimes i_{M}\right) \zeta\right],
\end{gathered}
$$

where $\odot$ denotes the Hadamard product. Then, since the additive constraints Equations (12)-(17) and $\exp \left[-i_{K M}-\left(\mathbf{I}_{K} \otimes i_{M}\right) \rho\right], \exp \left[-i_{K M}-\left(\mathbf{I}_{K} \otimes i_{M}\right) \Phi\right], \exp \left[-i_{G M}-\left(\mathbf{I}_{G} \otimes i_{M}\right) \vartheta\right], \exp \left[-i_{K}-\right.$ $\left.\left(\mathbf{I}_{K} \otimes i^{\prime}{ }_{M}\right) \phi\right], \exp \left[-i_{N M}-\left(\mathbf{I}_{\mathbf{N}} \otimes i^{\prime}{ }_{\mathbf{M}}\right) \varphi\right]$, and $\exp \left[-i_{N T M}-\left(\mathbf{I}_{N T} \otimes i^{\prime}{ }_{M}\right) \zeta\right]$ are constant, this optimization yields

$$
\mathbf{p}^{-}=\exp \left(-\mathbf{Z}^{\prime}\left(\mathbf{X}^{\prime}-\mathbf{Q h}\right)^{\prime}{ }_{-} \boldsymbol{\lambda}\right)\left(\left(\mathbf{I}_{K} \otimes i_{M}\right) \exp \left(-\mathbf{Z}^{\prime}\left(\mathbf{X}^{\prime}-\mathbf{Q h}\right)^{\prime}{ }_{-} \boldsymbol{\lambda}\right)\right)^{\odot(-1)},
$$




$$
\begin{gathered}
\mathbf{p}^{+}=\exp \left(-\mathbf{Z}^{\prime}\left(\mathbf{X}^{\prime}-\mathbf{Q h}\right)_{+} \boldsymbol{\lambda}\right)\left(\left(\mathbf{I}_{K} \otimes i_{M}\right) \exp \left(-\mathbf{Z}^{\prime}\left(\mathbf{X}^{\prime}-\mathbf{Q h}\right)_{+} \boldsymbol{\lambda}\right)\right)^{\odot(-1)}, \\
\mathbf{r}=\exp \left(-\mathbf{Z}^{\prime} \mathbf{D}^{\prime} \boldsymbol{\lambda}\right)\left(\left(\mathbf{I}_{G} \otimes i_{M}\right) \exp \left(-\mathbf{Z}^{\prime} \mathbf{D}^{\prime} \boldsymbol{\lambda}\right)\right)^{\odot(-1)}, \\
\mathbf{h}=\left(\exp \left(-\mathbf{Z}^{\prime}(\mathbf{Q})_{-} \boldsymbol{\lambda}\right)-\exp \left(-\mathbf{Z}^{\prime}(\mathbf{Q})_{+} \boldsymbol{\lambda}\right)\right)\left(\left(\mathbf{I}_{K} \otimes i^{\prime}{ }_{M}\right) \exp \left(-\mathbf{Z}^{\prime}(\mathbf{Q})_{-} \boldsymbol{\lambda}\right)-\exp \left(-\mathbf{Z}^{\prime}(\mathbf{Q})_{+} \boldsymbol{\lambda}\right)\right)^{\odot(-1)}, \\
\mathbf{f}=\exp \left(-\mathbf{B}^{\prime}\left(\mathbf{I}_{\mathbf{N}} \otimes i^{\prime}{ }_{T}\right) \boldsymbol{\lambda}\right)\left(\left(\mathbf{I}_{\mathbf{N}} \otimes i^{\prime}{ }_{\mathbf{M}}\right) \exp \left(-\mathbf{B}^{\prime}\left(\mathbf{I}_{\mathbf{N}} \otimes i_{T}^{\prime}\right) \boldsymbol{\lambda}\right)\right)^{\odot(-1)}, \\
\mathbf{w}=\exp \left(-\mathbf{V}^{\prime} \boldsymbol{\lambda}\right)\left(\left(\mathbf{I}_{N T} \otimes i_{M}^{\prime}\right) \exp \left(-\mathbf{V}^{\prime} \boldsymbol{\lambda}\right)\right)^{\odot(-1)},
\end{gathered}
$$

where $\odot(-1)$ is the Hadamard inverse; that is, the elementwise reciprocation.

\section{Empirical Result}

\subsection{Data Analysis}

In this study, the real Gross Domestic Product of ten Southeast Asian countries (Brunei, Cambodia, Laos, Indonesia, Malaysia, Myanmar, Philippines, Singapore, Thailand, and Vietnam) $\left(R G D P_{i t}\right)$ in aggregation represents the economic growth variable. For the independent variables, several tourism indicators are considered. In the tourism economics literature, the total number of international tourist arrivals (TourD $\left.D_{i t}\right)$ [34-36], the international tourism receipts $\left(T R_{i t}\right)[10,22,25,37]$, and the international tourism expenditures $\left(T E_{i t}\right)$ [38-40] are used as the tourism indicators. Also, we take the gross capital formation $\left(K_{i t}\right)$ and the real effective exchange rate $\left(E X R_{i t}\right)$ as the control variables in our empirical model.

The study focuses on Southeast Asian countries that have similar characteristics; hence, it would be reasonable to assume that the same model is relevant for all countries, and thus the panel kink regression with fixed effect GME estimator is applicable. Our empirical model can be written as

$$
\ln R G D P_{i t}=f\left(\ln T o u r D_{i t}, \ln T R_{i t}, \ln T E_{i t}, \ln K_{i t}, \ln E X R_{i t}\right) .
$$

All data were collected from the World Bank database and the Islamic Development Bank. The data are annual and cover the period 2004-2018, transformed into logarithms for use in the log-log equation. Thus, the estimated coefficients can represent the elasticity values. The descriptive statistics, namely mean, standard deviation, minimum values, and maximum values of the variables used in the study, are presented in Table 1.

Table 1. Descriptive statistics.

\begin{tabular}{lcccccc}
\hline & $\ln R$ GDP & $\ln$ TourD & $\operatorname{InTR}$ & $\ln T E$ & $\ln E X \boldsymbol{R}$ & $\ln \boldsymbol{C}$ \\
\hline Mean & 13.3383 & 15.0863 & 21.0848 & 7.8413 & 4.9170 & 23.7114 \\
Median & 12.4197 & 15.3396 & 21.8377 & 8.5674 & 3.7867 & 24.2072 \\
Maximum & 17.4025 & 17.2995 & 20.2454 & 7.0582 & 9.9934 & 26.4975 \\
Minimum & 10.1221 & 11.6869 & 0.5356 & 0.5288 & 0.2133 & 20.1595 \\
Std. Dev. & 2.6075 & 1.4173 & -0.091 & -0.1703 & 3.7180 & 1.6271 \\
Skewness & 0.3385 & -0.6591 & 1.9999 & 1.8102 & 0.0937 & -0.4353 \\
Kurtosis & 1.4738 & 2.7468 & 0.8934 & 1.1248 & 1.3154 & 2.1016 \\
\hline
\end{tabular}

The starting point of our econometric analysis is to check whether the variables contain panel unit roots. Then, we apply the panel unit root test (with intercept) of Levin, Lin, and Chu [41]. Table 2 shows the panel unit root statistics of our variables; we can see that the null hyphothesis of unit root is rejected for all variables when the intercept and trend are included in the test, indicating that all our data series are stationary at the level. 
Table 2. Panel Unit Root tests.

\begin{tabular}{|c|c|}
\hline Variable & \multirow[t]{2}{*}{ Level } \\
\hline & \\
\hline Intercept & $-3.7449^{* * *}$ \\
\hline Intercept + Trend & $-3.9887^{* * *}$ \\
\hline none & 30.5825 \\
\hline \multicolumn{2}{|c|}{$\ln$ TourD } \\
\hline Intercept & $-1.3821 * *$ \\
\hline Intercept + Trend & $0.0835^{* * *}$ \\
\hline none & 8.5974 \\
\hline \multicolumn{2}{|c|}{$\ln K$} \\
\hline Intercept & $-4.7596^{* * *}$ \\
\hline Intercept + Trend & $-3.6315^{* * *}$ \\
\hline none & 5.8888 \\
\hline \multicolumn{2}{|c|}{$\ln E X R$} \\
\hline Intercept & $-2.5656^{* * *}$ \\
\hline Intercept + Trend & $-2.1944^{* * *}$ \\
\hline none & 5.7989 \\
\hline \multicolumn{2}{|c|}{$\ln T E$} \\
\hline Intercept & $-2.1933^{* * *}$ \\
\hline Intercept + Trend & $-6.3352 * * *$ \\
\hline none & 5.7378 \\
\hline \multicolumn{2}{|c|}{$\operatorname{lnTR}$} \\
\hline Intercept & $-2.7878^{* * *}$ \\
\hline Intercept + Trend & $-3.8507^{* * *}$ \\
\hline none & 6.4930 \\
\hline
\end{tabular}

It is common for regression models to be plagued with the problem of multicollinearity when two or more regressors are highly correlated. Ciavolino and Indiveri [42] mentioned that this problem might occur in the parameter estimation when data points are fewer than the parameter estimates or in the presence of rank deficient regression matrices. This problem results in unstable estimates of regression coefficients and causes severe problems in the validation and interpretation of the model. To detect the presence of multicollinearity among our regressors, we used the variance inflation factor (VIF) and tolerance limit (TOL) $[43,44]$ as the diagnostic measures. The results of the tests are provided in Table 3. We note that the value of VIF > 10 [45] or the value of TOL 0 indicates the existence of collinearity among regressors $[43,44]$. From Table 3, we can observe that the VIF values of $\ln T O U R D$ and $\ln T R$ are greater than 10 and highly correlated with other regressors (see Table A1). Thus, the adoption of GME estimation is reasonable and applicable in this study. According to Golan, Judge, and Miller [16], the GME estimator can be used to handle the multicollinearity problem in regression analysis. If the number of support vector values are well specified, GME estimation is a very practical method to overcome the multicollinearity problem. They also showed that the GME estimator has a lower mean squared error than the least squares and maximum likelihood estimators in several sampling experiments, particularly when the data exhibit a high degree of collinearity. 
Table 3. Multicollinearity test results.

\begin{tabular}{|c|c|c|}
\hline Variable & VIF & TOL \\
\hline $\operatorname{lnTOURD}$ & 12.5137 & 0.0799 \\
\hline $\ln K$ & 4.8595 & 0.2058 \\
\hline $\ln E X R$ & 1.5304 & 0.6534 \\
\hline $\ln T E$ & 8.5817 & 0.1165 \\
\hline $\ln T R$ & 21.0593 & 0.0475 \\
\hline
\end{tabular}

\subsection{Testing the Kink Effect}

Before applying the panel kink regression, it is necessary to test for the existence of the nonlinear relationship between economic growth and tourism development variables. This study uses the entropy ratio test for the kink effect introduced in Sriboonchitta, et al. [32]. The null hypothesis of the entropy test is $H_{0}: \beta_{k}=\beta_{k}{ }^{-}=\beta_{k}{ }^{+}$, indicating no kink effect, whereas the alternative hypothesis $H_{a}: \beta_{k}{ }^{-} \neq \beta_{k}{ }^{+}$, indicating a threshold exists. If the null hypothesis is rejected, one should use the panel kink regression model. The entropy ratio statistic can be defined as

$$
E R=2\left|\mathbf{H}_{\mathbf{U}}\left(\beta_{k}^{-} \neq \beta_{k}^{+}\right)-\mathbf{H}_{\mathbf{R}}\left(\beta_{k}=\beta_{k}^{-}=\beta_{k}^{+}\right)\right|
$$

where $\mathbf{H}_{\mathbf{U}}$ is the unrestricted hypothesis (kink regression) and $\mathbf{H}_{\mathbf{R}}$ is the restricted hypothesis (linear regression).

Table 4 presents the test result of the kink effect for each independent variable against $\ln R G D P$, specifically including the entropy values for the linear and the kink models, the entropy ratio, the $p$-value, and the result interpretation for each predictor variable. We can see that there is a significant kink effect in $\ln T O U R D$ with the $p$-value of 0.0921 , but the kink effects for $\ln K, \ln E X R, \ln T E$, and $\ln T R$ are statistically insignificant, with the $p$-values of $0.1240,0.1484,0.2355$, and 0.1191 , respectively. According to this result, we, therefore, write out our empirical model as follows:

$$
\ln R G D P_{i t}=\beta_{1}^{-}\left(\ln T o u r D_{i t}-\gamma_{1}\right)_{-}+\beta_{1}^{+}\left(\ln \operatorname{Tour} D_{i t}-\gamma_{1}\right)_{+}+\beta_{2} K_{i t}+\beta_{3} \ln E X R_{i t}+\beta_{4} \ln T E_{i t}+\beta_{5} \ln T R_{i t}+u_{i}+\varepsilon_{i t}
$$

Table 4. Entropy ratio test.

\begin{tabular}{cccccc}
\hline & $\boldsymbol{H}_{\text {linear }}$ & $\boldsymbol{H}_{\text {kink }}$ & Entropy Ratio & $p$-Value & Interpretation \\
\hline $\ln T O U R D$ & 132.2198 & 133.5431 & $2.6466^{*}$ & 0.0921 & With kink effect \\
\hline $\ln K$ & 131.9620 & 133.1439 & 2.3638 & 0.1240 & No kink effect \\
\hline $\ln E X R$ & 131.1599 & 132.2039 & 2.0880 & 0.1484 & No kink effect \\
\hline $\ln T E$ & 131.1549 & 131.8585 & 1.4072 & 0.2355 & No kink effect \\
\hline $\ln T R$ & 131.6590 & 132.8732 & 2.4284 & 0.1191 & No kink effect
\end{tabular}

Note In this test, three supports for parameters and errors are specified; thus, the lower and upper bounds for these parameters and errors are $[-5,0,5]$ and $[-10,0,10]$, respectively. " $* "$ indicates significant at $10 \%$ level.

The above result provides a piece of strong evidence that there is a kink effect in the relationship between economic growth and total international arrivals (InTOURD). Hence, the whole sample of total international arrivals can be split into two regimes, according to the kink parameter $\gamma_{1}$. It is now confirmed that the relationship between economic growth and the number of tourist arrivals is mainly nonlinear. The result is in line with the previous findings in which a nonlinear effect of tourism growth on economic growth was found (see $[6,7,46])$.

\subsection{Empirical Estimation Results and Discussion}

After confirming the existence of the nonlinear effect of a tourism variable (international tourist arrivals) on economic growth, we then investigate and prove the performance 
and robustness of the GME estimator by comparing it with the fixed effect ordinary least squares (fixed effect) estimator of Zhang, Zhou, and Jiang [13], given the fixed parameters across individuals. Moreover, comparison is also made between the pooled ordinary least squares (pooled OLS) and the pooled GME, which simply are the OLS and GME techniques run on panel data. In other words, all individual-specific effects are ignored.

Since the GME estimator allows us to include the prior information on parameters by modifying the support values of the parameters to be estimated, we vary the number of supports as three supports (GME3), five supports (GME5), and seven supports (GME7). In sum, this section considers eight competing estimations consisting of fixed effect GME3, fixed effect GME5, fixed effect GME7, fixed effect OLS, pooled GME3, pooled GME5, pooled GME7, and pooled OLS.

The comparison of these estimations is based on root mean squared error (RMSE) and mean squared error (MSE). By definition, RMSE and MSE of an estimator measure the average difference between the estimator and what is estimated. Small MSE values are needed in statistics because they are closer to the actual data [47]. Therefore, we choose the best estimation based on the smallest values of RMSE and MSE. Additional discussion on panel data estimators can be found in Reed and Ye [48].

To have a better understanding of the results of panel kink regression, we compare the estimated parameter results of a panel linear regression models (Table 5) and panel kink regression models (Table 6). The MSE and RMSE are also adopted to compare the performance of these two models. According to MSE and RMSE values provided in the last two rows of Tables 5 and 6, we can observe that the MSE and RMSE values of panel kink regression are lower than linear regression for all cases, indicating the panel kink regression is appropriate for the analysis of the nonlinear effect of toursim development on the economic growth of Southeast Asian countries.

Table 5. Panel linear regreession with pooled GME, Fixed effect GME, and OLS estimates.

\begin{tabular}{|c|c|c|c|c|c|c|c|c|}
\hline \multirow[b]{2}{*}{ Variable } & \multicolumn{4}{|c|}{ Pooled Panel } & \multicolumn{4}{|c|}{ Fixed Effect Panel } \\
\hline & GME3 & GME5 & GME7 & OLS & GME3 & GME5 & GME7 & OLS \\
\hline$\beta_{1}$ & $\begin{array}{c}1.8936^{* * *} \\
(0.9834)\end{array}$ & $\begin{array}{c}1.8933^{* * *} \\
(0.9832)\end{array}$ & $\begin{array}{c}1.8936^{* * *} \\
(0.9834)\end{array}$ & $\begin{array}{c}1.8936^{* * *} \\
(0.9834)\end{array}$ & $\begin{array}{c}2.0234^{* * *} \\
(0.7993)\end{array}$ & $\begin{array}{c}2.2064^{* * *} \\
(0.7419)\end{array}$ & $\begin{array}{c}2.2037^{* * *} \\
(0.7029)\end{array}$ & $\begin{array}{l}2.3380 * \\
(1.2823)\end{array}$ \\
\hline$\beta_{2}$ & $\begin{array}{c}1.2738^{* * *} \\
(0.4421)\end{array}$ & $\begin{array}{l}1.2745^{* * *} \\
(0.4420)\end{array}$ & $\begin{array}{c}1.2738^{* * *} \\
(0.4421)\end{array}$ & $\begin{array}{c}1.2732^{* * * *} \\
(0.4401)\end{array}$ & $\begin{array}{c}1.3092 * * * \\
(0.4021)\end{array}$ & $\begin{array}{c}1.5352 * * * \\
(0.3121)\end{array}$ & $\begin{array}{c}1.5530 * * * \\
(0.3064)\end{array}$ & $\begin{array}{l}1.5093 \text { ** } \\
(0.7084)\end{array}$ \\
\hline$\beta_{3}$ & $\begin{array}{c}1.0882 \\
(0.5002)\end{array}$ & $\begin{array}{c}1.0882 \\
(0.5002)\end{array}$ & $\begin{array}{c}1.0882 \\
(0.5002)\end{array}$ & $\begin{array}{c}1.1093 \\
(0.4139)\end{array}$ & $\begin{array}{c}0.9282 \\
(0.8834)\end{array}$ & $\begin{array}{c}0.9180 \\
(1.1354)\end{array}$ & $\begin{array}{c}0.8673 \\
(1.1175)\end{array}$ & $\begin{array}{c}0.9335 \\
(1.1581)\end{array}$ \\
\hline$\beta_{4}$ & $\begin{array}{l}1.4024^{* * *} \\
(0.3432)\end{array}$ & $\begin{array}{l}1.4024^{* * *} \\
(0.3432)\end{array}$ & $\begin{array}{l}1.4051^{* * *} \\
(0.3411)\end{array}$ & $\begin{array}{c}1.3902^{* * * *} \\
(0.3432)\end{array}$ & $\begin{array}{c}1.2839 * * * \\
(0.3094)\end{array}$ & $\begin{array}{c}1.4086^{* * *} \\
(0.3496)\end{array}$ & $\begin{array}{c}1.4039 * * * \\
(0.3413)\end{array}$ & $\begin{array}{l}1.5002 * \\
(0.7716)\end{array}$ \\
\hline$\beta_{5}$ & $\begin{array}{l}1.1293 \text { * } \\
(0.5028)\end{array}$ & $\begin{array}{l}1.1293 \text { * } \\
(0.4982)\end{array}$ & $\begin{array}{l}1.1298 * \\
(0.5028)\end{array}$ & $\begin{array}{l}1.1209 * \\
(0.4286)\end{array}$ & $\begin{array}{c}-1.2320 * \\
(0.4019)\end{array}$ & $\begin{array}{l}1.0148 \text { * } \\
(0.5718)\end{array}$ & $\begin{array}{l}0.9909 * \\
(0.5612)\end{array}$ & $\begin{array}{l}1.2077 \text { * } \\
(0.6973)\end{array}$ \\
\hline $\begin{array}{c}\text { Max } \\
\text { Entropy }\end{array}$ & 140.2323 & 140.3928 & 140.3022 & & 159.993 & 159.6392 & 160.9823 & \\
\hline Adjusted $R^{2}$ & 0.9108 & 0.9109 & 0.9110 & 0.9088 & 0.9273 & 0.9358 & 0.9509 & 0.9210 \\
\hline $\begin{array}{c}\text { MSE } \\
\text { (linear) }\end{array}$ & 7.7590 & 7.7590 & 7.7587 & 7.8221 & 7.7584 & 7.7589 & 7.7335 & 7.6198 \\
\hline $\begin{array}{c}\text { RMSE } \\
\text { (linear) }\end{array}$ & 2.7855 & 2.7855 & 2.7854 & 2.8024 & 2.7853 & 2.7854 & 2.7466 & 2.7604 \\
\hline
\end{tabular}


Table 6. Panel kink regreession pooled GME, Fixed effect GME, and OLS estimates.

\begin{tabular}{|c|c|c|c|c|c|c|c|c|}
\hline \multirow[b]{2}{*}{ Variable } & \multicolumn{4}{|c|}{ Pooled Panel Kink } & \multicolumn{4}{|c|}{ Fixed Effect Panel Kink } \\
\hline & GME3 & GME5 & GME7 & OLS & GME3 & GME5 & GME7 & OLS \\
\hline$\beta_{1}^{-}$ & $\begin{array}{l}2.0926^{* * *} \\
(0.9669)\end{array}$ & $\begin{array}{c}2.2062 * * * \\
(0.7353)\end{array}$ & $\begin{array}{l}2.2023^{* * *} \\
(0.6949)\end{array}$ & $\begin{array}{c}3.7587^{* * *} \\
(0.9360)\end{array}$ & $\begin{array}{l}2.2113 * * * \\
(0.7387)\end{array}$ & $\begin{array}{l}2.2064^{* * *} \\
(0.7419)\end{array}$ & $\begin{array}{c}2.2037^{* * *} \\
(0.7029)\end{array}$ & $\begin{array}{c}3.7710^{* * *} \\
(0.9390)\end{array}$ \\
\hline$\beta_{1}^{+}$ & $\begin{array}{l}1.0287^{* * *} \\
(0.7455)\end{array}$ & $\begin{array}{l}1.4256^{* * *} \\
(0.6817)\end{array}$ & $\begin{array}{c}1.5424^{* * *} \\
(0.6645)\end{array}$ & $\begin{array}{c}2.1477^{* * *} \\
(0.7215)\end{array}$ & $\begin{array}{c}1.4861 * * * \\
(0.7199)\end{array}$ & $\begin{array}{c}1.4239 * * * \\
(0.7218)\end{array}$ & $\begin{array}{c}1.5415 * * * \\
(0.7049)\end{array}$ & $\begin{array}{c}2.2818^{* * *} \\
(0.7618)\end{array}$ \\
\hline$\beta_{2}$ & $\begin{array}{c}1.5094^{* * *} \\
(0.3365)\end{array}$ & $\begin{array}{l}1.5363^{* * *} \\
(0.3083)\end{array}$ & $\begin{array}{c}1.5541^{* * *} \\
(0.3023)\end{array}$ & $\begin{array}{c}1.2769 * * * \\
(0.3257)\end{array}$ & $\begin{array}{c}1.5349 * * * \\
(0.3114)\end{array}$ & $\begin{array}{c}1.5352 * * * \\
(0.3121)\end{array}$ & $\begin{array}{c}1.5530 * * * \\
(0.3064)\end{array}$ & $\begin{array}{c}1.2904^{* * *} \\
(0.3275)\end{array}$ \\
\hline$\beta_{3}$ & $\begin{array}{c}1.1467 \\
(0.8859)\end{array}$ & $\begin{array}{c}0.9216 \\
(0.8600)\end{array}$ & $\begin{array}{c}0.8704 \\
(0.8495)\end{array}$ & $\begin{array}{l}1.5846 * \\
(0.8573)\end{array}$ & $\begin{array}{c}0.9008 \\
(1.1330)\end{array}$ & $\begin{array}{c}0.9180 \\
(1.1354)\end{array}$ & $\begin{array}{c}0.8673 \\
(1.1175)\end{array}$ & $\begin{array}{c}2.0211 \\
(1.1581)\end{array}$ \\
\hline$\beta_{4}$ & $\begin{array}{c}1.4823^{* * *} \\
(0.3599)\end{array}$ & $\begin{array}{l}1.4077^{* * *} \\
(0.3319)\end{array}$ & $\begin{array}{c}1.4034^{* * *} \\
(0.3249)\end{array}$ & $\begin{array}{c}1.4480^{* * *} \\
(0.3483)\end{array}$ & $\begin{array}{c}1.4111^{* * *} \\
(0.3487)\end{array}$ & $\begin{array}{c}1.4086^{* * *} \\
(0.3496)\end{array}$ & $\begin{array}{c}1.4039 * * * \\
(0.3413)\end{array}$ & $\begin{array}{c}1.3766^{* * *} \\
(0.3716)\end{array}$ \\
\hline$\beta_{5}$ & $\begin{array}{l}1.1106 \text { * } \\
(0.6089)\end{array}$ & $\begin{array}{l}1.0145 * \\
(0.5664)\end{array}$ & $\begin{array}{l}0.9907 * \\
(0.5557)\end{array}$ & $\begin{array}{l}1.7446 \text { * } \\
(0.5893)\end{array}$ & $\begin{array}{c}-1.0441 \text { * } \\
(0.5704)\end{array}$ & $\begin{array}{l}1.0148 * \\
(0.5718)\end{array}$ & $\begin{array}{l}0.9909 * \\
(0.5612)\end{array}$ & $\begin{array}{l}1.7753 \text { * } \\
(0.5935)\end{array}$ \\
\hline$\gamma_{1}$ & $\begin{array}{c}13.4003^{* * *} \\
(0.0114)\end{array}$ & $\begin{array}{c}13.8111^{* * * *} \\
(0.0415)\end{array}$ & $\begin{array}{c}13.9188^{* * *} \\
(0.0215)\end{array}$ & $\begin{array}{c}13.4020 * * * \\
(0.0315)\end{array}$ & $\begin{array}{c}13.8167^{* * *} \\
(0.0145)\end{array}$ & $\begin{array}{c}13.8112 * * * \\
(0.0254)\end{array}$ & $\begin{array}{c}13.9187^{* * *} \\
(0.0215)\end{array}$ & $\begin{array}{c}13.4007^{* * *} \\
(0.0315)\end{array}$ \\
\hline $\begin{array}{c}\text { Max } \\
\text { Entropy }\end{array}$ & 156.4839 & 160.4608 & 162.139 & & 197.6748 & 195.0704 & 200.0582 & \\
\hline Adjusted $R^{2}$ & 0.9344 & 0.9572 & 0.9716 & 0.9319 & 0.9591 & 0.9572 & 0.9716 & 0.9372 \\
\hline $\begin{array}{c}\text { MSE } \\
\text { (Kink) }\end{array}$ & 6.0859 & 5.9735 & 5.7792 & 6.2607 & 5.9472 & 5.9733 & 5.7790 & 6.2431 \\
\hline RMSE(Kink) & 2.8871 & 2.4441 & 2.4040 & 2.9121 & 2.4386 & 2.4440 & 2.4038 & 2.9086 \\
\hline
\end{tabular}

Table 6 presents the estimation results for the different panel kink regression formats. The estimated parameters from the pooled panel data model are reported in columns 1-4, while those of the fixed effect panel data model in columns 5-8. The lower part of Table 6 shows the results of the goodness of fit for each estimation, including Adjusted $R^{2}$, and MSE and RMSE of both the panel data kink regression and panel data linear regression methods. The results show that the fixed effect GME7 is superior to all estimations based on its lowest MSE and RMSE. Besides, the Adjusted $R^{2}$ value of this estimation is 0.9716 implying that the tourism development variables can explain 97.16 percent of Southeast Asian economic change, and this value is higher than the Adjusted $R^{2}$ of other competing estimations. Thus, we can conclude that the fixed effect GME7 is the efficient estimator for our empirical model.

The results of the best fit estimation are shown in column 7 . We note that the individual effects are treated as fixed, indicating that the individual-specific intercepts are fixed across the Southeast Asian countries. In addition, as mentioned in Section 4.3, there is a significant nonlinear relationship between the number of international tourist arrivals and the Southeast Asian economic growth. This means that the number of tourist arrivals is split into two regimes according to the estimated kink parameter $\gamma_{1}$, with different outcome effects on Southeast Asian economic growth. Therefore, our result discussion is based on this model specification.

From Table 6, we notice that all explanatory variables, except for the real effective exchange rate, significantly affect the Southeast Asian economy. Moreover, the capability of our panel kink regression allows for the nonlinear impacts of the number of tourist arrivals on growth; hence the impacts are separated into two regimes, where regime 1 $\left(\ln \text { Tour } D_{i t}-\gamma_{1}\right)_{-}$and regime $2\left(\ln \operatorname{Tour} D_{i t}-\gamma_{1}\right)_{+}$are interpreted as the low and the high number of tourist arrivals regimes, respectively. As shown in Table 6, if the number of tourist arrivals is less than 13.9187 (exp (13.9187) or 1,108,701 visitors/year), a 1\% increase in tourist arrivals may contribute to a $2.2037 \%$ increase in Southeast Asian economic growth 
On the other hand, when the number of tourist arrivals is greater than 1,108,701 visitors/year, there is a weak positive relationship between tourism expansion and economic growth. In this high number of tourist arrivals regime, a 1\% increase in tourist arrivals may bring about a $1.5415 \%$ increase in economic growth. We would like to note that the panel data of ten Southeast Asian countries is used; thus, the number of 1,108,701 visitors/year can be viewed as the average number of tourist arrivals of Southeast Asian countries.

According to the result of the nonlinear effect of tourist arrivals on economic growth, we can explain that, at the low level of tourist arrivals, tourism can improve the living standards of the domestic people and enhance the domestic market. Nevertheless, obstacles are still in the way. The weaker positive impacts of tourism on economic growth are possible with the presence of tourism leakage in the high tourism demand regime. Two types of tourism leakage can be distinguished. The first is the import leakage, which occurs when tourists purchase the products that the Southeast Asian countries cannot supply and need to import from elsewhere. Thus, in this scenario, the benefits from more tourist arrivals are partly sent to other countries outside Southeast Asia. According to Cheang [49], the levels of tourism leakage of most of the Southeast Asian countries are high, accounting for 50\% of the gross tourism earnings. Thus, we can say that the substantial tourist arrivals to Southeast Asia may bring a weak positive effect to the Southeast Asian economy, as many Southeast Asian countries lack the reliable supply chain of the products and services for tourists. The second type of tourism leakage is the export leakage, which mostly occurs in poor developing nations where multinational corporations and large foreign businesses are the only ones that possess the necessary capital to invest in the construction of tourism infrastructure and facilities, resulting in an increased capital outflow when these overseas investors take their profits back to their country of origin. In the Southeast Asian region, some sources of leakage are unavoidable, examples of which are the foreign-owned hotels, airlines and restaurants.

In addition, this study finds that the tourism receipts and tourism expenditure positively influence the Southeast Asian economies. A 1\% increase in gross capital formation and tourism receipts accounts for a $1.5530 \%$ and $0.9909 \%$ increase in the economic growth of Southeast Asian countries, respectively.

Finally, in the case of gross capital formation and real effective exchange rate, the coefficients of these two control variables are positive, but only that of gross capital formation is significant. This means that the Southeast Asian economy is unaffected by changes in the exchange rate. Our result is consistent with the findings of Hashim, Sifat, and Mohamad [50] and Hashim, Mohamad and Sifat [51] who found a significant impact of capital formation on economic growth. Meanwhile, the effects of exchange rates were inconclusive.

\section{Conclusions}

It is believed that tourism development has a positive contribution to the overall economy of tourism destinations. However, there has been no consensus regarding whether tourism development has a positive or negative effect on economic growth. Moreover, previous empirical studies found that the linear model sometimes fails to capture the true relationship between tourism development and economic growth, and divergent results are usually found. The reason is that there may exist a nonlinear relationship between tourism and economic growth. Thus, the main contribution of this study is from its attempts to clarify the relationship between tourism development and economic growth and reevaluate whether the relationship between these two variables in Southeast Asian countries is linear or nonlinear. To answer this question, we employ the panel kink regression model to describe the complex nonlinear relationships between Southeast Asian economic growth and tourism. Moreover, as we may face the small sample data of the Southeast Asian countries (especially Lao, Cambodia, and Myanmar), the panel kink model may have illposed problems (the number of unknown parameters exceeds the number of observations, or the underlying distribution is unknown). Therefore, the Generalized Maximum Entropy (GME) estimation is applied for estimating our model. 
The main conclusions are as follows:

(1) Our result confirms a nonlinear relationship between the number of tourist arrivals and the Southeast Asian economy. In particular, when the number of tourist arrivals is less than $13.9187(\exp (13.9187)=1,108,701$ visitors/year), an increase in the number of tourist arrivals contributes a positive impact to Southeast Asian economic growth. However, the impact of tourism development in Southeast Asian economic growth becomes weak when the number of visitors is greater than 1,108,701 visitors/year. We indeed find positive impacts of tourism on Southeast Asian economic growth in both tourism demand regimes, with the effect of the low tourist arrivals regime being relatively larger. This result is consistent with Chang, Khamkaew, McAleer, and Tansuchat [6], who found the increase in the tourist arrivals to enhance economic growth in both regimes, with the effect of the low tourist arrivals regime being relatively larger. Based on these results, there may be some doubt as to why tourist arrivals make a weak contribution to economic growth in the Southeast Asia. However, in the literature, several studies confirmed that the relationship between tourism development and economic growth can be mixed. Po, and Huang [46], Bilen, Yilanci, and Eryüzlü [52] and Chiang, Sung, and Lei [7] suggested that the tourismgrowth nexus depends on an individual country's economic development and tourism specialization. Thus, different degrees of the impacts of tourism on economic growth are reasonable. Our result is in line with these recent empirical studies.

(2) Our panel kink model with seven supports has a better explanation for our tourismgrowth model than other linear and nonlinear types of models. In addition, GME estimation is found to be more efficient than pooled least squares and fixed effect least squares. Our finding is consistent with previous studies that found the superiority of the GME estimation over those conventional estimations $[12,14,30]$.

(3) Tourism receipts and tourism expenditures tend to contribute to the Southeast Asian economy positively. According to our study results, we conclude that tourism has become a relevant sector of the Southeast Asian economy and has become one of the viable and sustainable economic development options for both high and low tourist arrivals regimes. As expected, the impact of the international tourism expenditures and tourism receipts is similar as both are similar international tourism indicators. Brida, Cortes-Jimenez, and Pulina [53] mentioned that it is widely accepted that the adequate proxy of the inbound tourism demand in a country is tourism expenditures (generally expressed in terms of tourism receipts). Consistent with the findings of Chen, Chiou-Wei [23], Chang, Khamkaew, McAleer, and Tansuchat [6], and Ridderstaat, Croes and Nijkamp [10], among others, our study confirmed the positive contribution of tourism development to the economic growth of Southeast Asian countries.

Based on these results, this study presents the following policy recommendations:

(1) The first implication is that the impact of the number of tourist arrivals becomes weaker on the Southeast Asian economy in the high tourist arrivals regime. The possible reason is that those tourists purchase the products that the Southeast Asian countries cannot supply and need to import from elsewhere; the benefits from more tourist arrivals are partly sent to other countries outside Southeast Asia (import leakage). Furthermore, tourism export leakage may be another reason for this result. Most of the tourism-related businesses in Southeast Asia belong to foreigners or multinational corporations; thus, these overseas investors will take their profits back to their country of origin when they gain a higher income in the high tourist arrivals regime. We suggest that the linkages between domestic industries and tourism should be tightened, and the tourism import and export leakages should be restricted to sustain Southeast Asian economies

(2) The other policy implication derived from this study is that Southeast Asian countries can improve their economic growth performance, not only by investing in the traditional sources of growth such as technology, foreign direct investment, infrastructure, and human development, but also in the tourism industry to provide a reliable, continuous, competitively priced supply of the required products or services and of a consistent quality to deal with the presence of tourism leakage in the high tourism demand regime. 
(3) Gross capital formation impacts economic growth positively; thus, Southeast Asian countries should accumulate more capital goods to replace the older ones used to produce goods and services, resulting in higher economic growth.

Finally, this work could be of interest to policymakers, as it emphasizes the strong relationship between economic development and international tourism demand in Southeast Asia. Overall, we suggest that Southeast Asian countries should support or subsidize more locally-owned hotels, airlines, and restaurants when having more international tourist arrivals to achieve higher economic growth in the long run.

For further study, we suggest considering other indicators of economic growth, as GDP does not reflect the sustainability performance and wealth inequality (Hashim, Sifat, and Mohamad, 2018); thus, we suggest investigating the impact of tourism on other economic growth indicators, such as credit and the enforcement of contracts [54] and the Genuine Progress Indicator (GPI) [51]. These new indexes will provide a different point of view in defining the nonlinear tourism and economic growth nexus.

Author Contributions: Conceptualization, W.Y. and P.M.; data curation, W.S. and P.M.; methodology, W.Y. and W.S.; visualization, writing-original draft, W.Y. and P.M.; writing-review and editing, W.Y. and P.M. All authors have read and agreed to the published version of the manuscript.

Funding: Center of Excellence in Econometrics, Faculty of Economics, Chiang Mai University, Thailand.

Data Availability Statement: The data used in the empirical analyses are available online at the CEIC database, World Bank database. The data, however, are available upon request.

Acknowledgments: The authors would like to thank Laxmi Worachai for her help and constant support. This work is supported by the Center of Excellence in Econometrics, Faculty of Economics, Chiang Mai University, Thailand. We also would like to thank the academic editor and four reviewers for their valuable comments and suggestions.

Conflicts of Interest: The authors declare no conflict of interest.

\section{Appendix A}

Table A1. Correlation matrix.

\begin{tabular}{lrrrrrr}
\hline & $\ln$ TOURD & $\ln T R$ & $\ln T E$ & $\ln K$ & $\ln G D P$ & $\ln E \boldsymbol{X}$ \\
\hline $\ln T$ OURD & 1.0000 & & & & & \\
$\ln T R$ & 0.7230 & 1.0000 & & & & \\
$\ln T E$ & 0.5010 & 0.4082 & 1.0000 & & & \\
$\ln K$ & 0.4350 & 0.3874 & 0.5024 & 1.0000 & & \\
$\ln \mathrm{GDP}$ & 0.0661 & 0.0834 & 0.1840 & -0.0583 & 1.0000 & \\
$\ln E X$ & 0.0028 & 0.2001 & 0.0023 & -0.0936 & 0.9255 & 1.0000 \\
\hline
\end{tabular}

\section{References}

1. Belloumi, M. The relationship between tourism receipts, real effective exchange rate and economic growth in Tunisia. Int. J. Tour. Res. 2010, 12, 550-560. [CrossRef]

2. Clancy, M.J. Tourism and development: Evidence from Mexico. Ann. Tour. Res. 1999, 26, 1-20. [CrossRef]

3. Ertugrul, H.M.; Mangir, F. The tourism-led growth hypothesis: Empirical evidence from Turkey. Curr. Issues Tour. 2013, 18, 633-646. [CrossRef]

4. Tugcu, C.T. Tourism and the economic growth nexus revisited: A Panel causality analysis for the case of the Mediterranean region. Tour Manag. 2014, 42, 207-212. [CrossRef]

5. Lee, C.C.; Chien, M.S. Structural breaks, tourism development, and economic growth: Evidence from Taiwan. Math. Comput. Simul. 2008, 77, 358-368. [CrossRef]

6. Chang, C.-L.; Khamkaew, T.; McAleer, M. IV Estimation of a Panel Threshold Model of Tourism Specialization and Economic Development. Tour. Econ. 2012, 18, 5-41. [CrossRef]

7. Chiang, G.-N.; Sung, W.-Y.; Lei, W.-G. Regime-Switching Effect of Tourism Specialization on Economic Growth in Asia Pacific Countries. Economies 2017, 5, 23. [CrossRef]

8. Valadkhani, A.; O' Mahony, B. Identifying structural changes and regime switching in growing and declining inbound tourism markets in Australia. Curr. Issues Tour. 2018, 21, 277-300. [CrossRef] 
9. Wang, Y.-S. Research Note: Threshold Effects on Development of Tourism and Economic Growth. Tour. Econ. 2012, 18, 1135-1141. [CrossRef]

10. Ridderstaat, J.; Croes, R.; Nijkamp, P. Tourism and Long-run Economic Growth in Aruba. Int. J. Tour. Res. 2013, 16, 472-487. [CrossRef]

11. Hsiao, C. Analysis of Panel Data; Cambridge University Press: Cambridge, UK, 2013.

12. Kareem, O.I. A reassessment of tourism-exports led growth hypothesis in Africa. Am. J. Tour. Res. 2013, 2, 130-140. [CrossRef]

13. Tibprasorn, P.; Maneejuk, P.; Sriboochitta, S. Generalized Information Theoretical Approach to Panel Regression Kink Model. Thai J. Math. 2017, 133-145.

14. Zhang, Y.; Zhou, Q.; Jiang, L. Panel kink regression with an unknown threshold. Econ. Lett. 2017, 157, 116-121. [CrossRef]

15. Maneejuk, P.; Yamaka, W.; Sriboonchitta, S. Entropy inference in smooth transition kink regression. Commun. Stat. Simul. Comput. 2020, 1-24. [CrossRef]

16. Button, K.S.; Ioannidis, J.P.; Mokrysz, C.; Nosek, B.A.; Flint, J.; Robinson, E.S.; Munafò, M.R. Power failure: Why small sample size undermines the reliability of neuroscience. Nat. Rev. Neurosci. 2013, 14, 365-376. [CrossRef] [PubMed]

17. Golan, A.; Judge, G.; Miller, D. Maximum Entropy Econometrics: Robust Estimation with Limited Data; John Wiley: Chichester, $\mathrm{UK}, 1996$.

18. Akdeniz, F.; Çabuk, A.; Güler, H. Generalized maximum entropy estimators: Applications to the portland cement dataset. Open Stat. Probab. J. 2011, 3, 13-20. [CrossRef]

19. Balassa, B. Exports and economic growth: Further evidence. J. Dev. Econ. 1978, 5, 181-189. [CrossRef]

20. Antonakakis, N.; Dragouni, M.; Filis, G. How strong is the linkage between tourism and economic growth in Europe? Econ. Model 2015, 44, 142-155. [CrossRef]

21. Khanal, A.; Rahman, M.M.; Khanam, R.; Velayutham, E. Are Tourism and Energy Consumption Linked? Evidence from Australia. Sustainability 2021, 13, 10800. [CrossRef]

22. Brida, J.G.; Carrera, E.; Risso, W.A. Tourism's impact on long-run Mexican economic growth. Econ. Bull. 2008, 3, 1-10.

23. Balaguer, J.; Cantavella-Jordá, M. Tourism as a long-run economic growth factor: The Spanish case. Appl. Econ. 2002, 34, 877-884. [CrossRef]

24. Chen, C.-F.; Chiou-Wei, S.Z. Tourism expansion, tourism uncertainty and economic growth: New evidence from Taiwan and Korea. Tour. Manag. 2009, 30, 812-818. [CrossRef]

25. Lee, C.-C.; Chang, C.-P. Tourism development and economic growth: A closer look at Panels. Tour. Manag. 2008, 29, 180-192. [CrossRef]

26. Dritsakis, N. Tourism as a Long-Run Economic Growth Factor: An Empirical Investigation for Greece Using Causality Analysis. Tour. Econ. 2004, 10, 305-316. [CrossRef]

27. Arslanturk, Y.; Balcilar, M.; Ozdemir, Z.A. Time-varying linkages between tourism receipts and economic growth in a small open economy. Econ. Model. 2011, 28, 664-671. [CrossRef]

28. Tang, C.F.; Tan, E.C. How stable is the tourism-led growth hypothesis in Malaysia? Evidence from disaggregated tourism markets. Tour. Manag. 2013, 37, 52-57. [CrossRef]

29. Isik, C.; Dogru, T.; Turk, E.S. A nexus of linear and non-linear relationships between tourism demand, renewable energy consumption, and economic growth: Theory and evidence. Int. J. Tour. Res. 2017, 20, 38-49. [CrossRef]

30. Zhang, J.; Cheng, L. Threshold effect of tourism development on economic growth following a disaster shock: Evidence from the Wenchuan earthquake, PR China. Sustainability 2019, 11, 371. [CrossRef]

31. Jaynes, E.T. Information Theory and Statistical Mechanics. Phys. Rev. 1957, 106, 620-630. [CrossRef]

32. Shannon, C.E. A mathematical theory of communication. Bell Syst. Tech. J. 1948, 27, 379-423. [CrossRef]

33. Sriboochitta, S.; Yamaka, W.; Maneejuk, P.; Pastpipatkul, P. A Generalized Information Theoretical Approach to Non-linear Time Series Model. In Foundations of Computational Intelligence Volume 3; Springer Science and Business Media LLC: Berlin, Germany, 2017; Volume 2, pp. 333-348.

34. Pukelsheim, F. The three sigma rule. Am. Stat. 1994, 48, 88-91.

35. Gunduz, L.; Hatemi, -J.A. Is the tourism-led growth hypothesis valid for Turkey? Appl. Econ. Lett. 2005, 12, 499-504. [CrossRef]

36. Katircioglu, S.T. Revisiting the tourism-led-growth hypothesis for Turkey using the bounds test and Johansen approach for cointegration. Tour. Manag. 2009, 30, 17-20. [CrossRef]

37. Tang, C.F.; Abosedra, S. Tourism and growth in Lebanon: New evidence from bootstrap simulation and rolling causality approaches. Empir. Econ. 2015, 50, 679-696. [CrossRef]

38. Tang, J.; Sriboonchitta, S.; Ramos, V.; Wong, W.-K. Modelling dependence between tourism demand and exchange rate using the copula-based GARCH model. Curr. Issues Tour. 2014, 19, 876-894. [CrossRef]

39. Issik, C.; Kasımatı, E.; Ongan, S. Analyzing the causalities between economic growth, financial development, international trade, tourism expenditure and/on the $\mathrm{CO}^{2}$ emissions in Greece. Energy Sources B Econ. Plan. Policy 2017, 12, 665-673. [CrossRef]

40. Aslan, A. Does tourism cause growth? Evidence from Turkey. Curr. Issues Tour. 2015, 19, 1176-1184. [CrossRef]

41. Song, H.; Li, G.; Witt, S.F.; Fei, B. Tourism Demand Modelling and Forecasting: How Should Demand Be Measured? Tour. Econ. 2010, 16, 63-81. [CrossRef]

42. Levin, A.; Lin, C.-F.; Chu, C.-S.J. Unit root tests in panel data: Asymptotic and finite-sample properties. J. Econ. 2002, 108, 1-24. [CrossRef] 
43. Ciavolino, E.; Indiveri, G. Entropy-based estimators in the presence of multicollinearity and outliers. In Multicriteria and Multiagent Decision Making with Applications to Economics and Social Sciences; Springer: Berlin/Heidelberg, Germany, 2013 ; pp. 65-76.

44. Kutner, M.H.; Nachtsheim, C.; Neter, J. Applied Linear Regression Models; McGraw-Hill: New York, NY, USA, 2004.

45. Marquaridt, D.W. Generalized Inverses, Ridge Regression, Biased Linear Estimation, and Nonlinear Estimation. Technometrics 1970, 12, 591-612. [CrossRef]

46. Curto, J.D.; Pinto, J.C. The corrected VIF (CVIF). J. Appl. Stat. 2010, 38, 1499-1507. [CrossRef]

47. Po, W.-C.; Huang, B.-N. Tourism development and economic growth-a nonlinear approach. Phys. A Stat. Mech. Its Appl. 2008, 387, 5535-5542. [CrossRef]

48. Fitrianto, A.; Musakkal, N.F.K. Panel Data Analysis for Sabah Construction Industries: Choosing the Best Model. Procedia Econ. Financ. 2016, 35, 241-248. [CrossRef]

49. Reed, W.R.; Ye, H. Which panel data estimator should I use? Appl. Econ. 2011, 43, 985-1000. [CrossRef]

50. Chheang, V. Hun Sen's Talks and Cambodias Tourism Development: The discourse of power. Ritsumeikan J. Asia Pac. Stud. 2009, $25,85-105$.

51. Hashim, M.; Sifat, I.M.; Mohamad, A. GDP vs genuine progress quantification of economic performance in South Korea and Malaysia. Econ. Bus. Lett. 2018, 7, 169-178. [CrossRef]

52. Hashim, M.; Mohamad, A.; Sifat, I.M. The sustainable development consequences of IMF debt vs. capital control: Comparing progress in GPI and GDP terms for Korea and Malaysia. J. Clean. Prod. 2019, 234, 725-742. [CrossRef]

53. Bilen, M.; Yilanci, V.; Eryüzlü, H. Tourism development and economic growth: A panel Granger causality analysis in the frequency domain. Curr. Issues Tour. 2015, 20, 27-32. [CrossRef]

54. Brida, J.G.; Cortes-Jimenez, I.; Pulina, M. Has the tourism-led growth hypothesis been validated? A literature review. Curr. Issues Tour. 2016, 19, 394-430. [CrossRef] 